\title{
Comparative Analysis of Three Structures of Second-Order Generalized Integrator and Its Application to Phase-Locked Loop of Linear Kalman Filter
}

\author{
Bo Zeng ${ }^{(D},{ }^{1}$ Yuxiang Sun, ${ }^{2,3}$ and Shaojun Xie ${ }^{1}$ \\ ${ }^{1}$ College of Automation Engineering, Nanjing University of Aeronautics and Astronautics, Nanjing City 211106, China \\ ${ }^{2}$ School of Management \& Engineering, Nanjing University, Nanjing City 210093, China \\ ${ }^{3}$ School of Computing and Engineering, University of Derby, Derby City DE22 1GB, UK
}

Correspondence should be addressed to Bo Zeng; tsangbo@nuaa.edu.cn

Received 6 December 2021; Revised 10 January 2022; Accepted 27 January 2022; Published 12 February 2022

Academic Editor: Haibin Lv

Copyright $(2022$ Bo Zeng et al. This is an open access article distributed under the Creative Commons Attribution License, which permits unrestricted use, distribution, and reproduction in any medium, provided the original work is properly cited.

The present work explores the power quality problems of a microgrid in the aviation field, such as frequency offset or waveform distortion, caused by voltage imbalance and nonlinear load, to ensure the efficient and stable flight of aircraft, unmanned aerial vehicles, and other aircraft. There are many problems such as excessive harmonics, voltage imbalance, and direct current (DC) component in aviation variable frequency power supply voltage in microgrid under different conditions. Therefore, three kinds of second-order generalized integrators (SOGIs) with different structures are combined with linear Kalman filter phase-locked loops (PLLs). Besides, intelligent sensors are utilized for signal processing. Finally, simulation experiments are conducted to compare three SOGIs. The results show that the system is stable when the parameters $k_{1}=738.955^{3}, k_{2}=1092108.98405, k_{3}=1477.91$, and $T_{s}=0.000125 \mathrm{~s}$ and $k$ ranges in $[0.5,3]$. The angular frequency of PLL output is very low under the problems of many harmonics, three-phase voltage imbalance, and DC component $\omega_{g}$. The angular frequency $\omega_{g}$ output by the PLL finally changes linearly with a change rate of $400 \pi \mathrm{rad} / \mathrm{s}^{2}$, so that the output phase angle $\theta_{g}$ reaches a stable state. Thus, the proposed steady-state linear Kalman filter phase locking can accurately phase-lock the aviation variable frequency power supply. It provides an important reference for the power supply module in the microgrid to select the appropriate second-order generalized integrator to realize the accurate phase locking of the phase-locked loop under different conditions.

\section{Introduction}

Electricity is one of the essential elements for the normal operation of modern society. Most of the world uses coal, oil, or other nonrenewable energy as the main fuel to provide electricity, which makes the depletion of nonrenewable energy and environmental pollution increasingly serious. Therefore, using clean renewable energy instead of traditional energy has gradually become an inevitable trend. In this context, microgrid uses diversified and clean new energy, attracting increasingly more attention from all countries in the world as an environmentally friendly, efficient, decentralized, and flexible power generation way. It has become a critical path to solve the contradiction between energy and the environment. The emergence of microgrid, a distributed generation (DG) method, furnishes the large power grid with a powerful supplement. Large-scale access to power grids has realized the coordination between main power grids, local power grids, and microgrids, making transmission modes more flexible [1]. In this kind of power supply structure, the interaction between users and the grid makes the power quality and the reliability of the power supply increase significantly [2]. In aviation, variable frequency power supply is an important part of the aircraft power supply system, which has the advantages of highpower generation efficiency and no need for constant installation and converter $[3,4]$. The aviation variable frequency power supply is used as the power supply of the microgrid and is integrated into the power grid through the converter as the power interface; meanwhile, the phase- 
locked loop (PLL) is used to realize the high-power factor operation of the aviation rectifier. The wide operating frequency range of aviation variable frequency power supply (typically $360 \sim 800 \mathrm{~Hz}$ ) puts forward high requirements for PLL.

The steady-state linear Kalman filter PLL [5-8] (SSLKFPLL) is a common PLL used in multi-electric aircraft converters. SSLKF-PLL provides excellent phase-locking performance for aviation variable frequency power supplies with a wide operating frequency range. SSLKF-PLL is an adaptive phase-frequency estimation algorithm based on a third-order linear steady observation model and a predictive correction model. It employs three different control units to estimate the phase angle, angular frequency, and angular frequency acceleration, respectively $[9,10]$. Therefore, compared with conventional synchronous coordinate system software PLL and the PLL based on discrete Fourier transformation [11], SSLKF-PLL has the advantages of fast dynamic response, high phase-locked accuracy, and good filtering performance. However, in the presence of highvoltage harmonics, three-phase voltage imbalance, and a direct current (DC) component in aviation inverter power supplies, the phase angle output by SSLKF-PLL contains a high-frequency component, which can affect phase-locking accuracy. Therefore, using intelligent sensors for alternating current (AC) voltage signal processing is also excessively significant. The aviation frequency conversion power supply has many voltage harmonics, three-phase voltage imbalance, and DC components. Therefore, to realize the fast and accurate phase locking of SSLKF, when using intelligent sensors to process the AC voltage in the frequency conversion power supply, a second-order generalized integrator (SOGI) can be added to the front stage of SSLKF-PLL. SOGI is a common second-order filter, which can generate two mutually orthogonal signals at the same time, and its transfer function has infinite gain at a specific frequency. Different SOGIs with different structures are applied to PLL, and different results can be obtained under different supply voltages [12-14]. The literature [15] proposed three kinds of SOGIs with different structures and applied them to the common three-phase synchronous coordinate PLL. The authors gained different results of phase locking and different adaptability to the power grid when the three-phase input voltage was the constant frequency and the threephase input voltage contained harmonics, subharmonics, and interharmonics. It provides an important reference for selecting different second-order generalized integrator structures for phase-locked loop under different input voltage conditions in aviation variable frequency power supply.

Here, based on the linear Kalman filter PLL, the intelligent sensor is used to process the AC voltage in the frequency conversion power supply, and SOGIs of different structures mentioned in reference [15] are added. The central angular frequency of the SOGI is obtained by feedback from the linear Kalman filter PLL. Moreover, the central angular frequency is a variable with time, so a highorder PLL system with strong nonlinearity is formed. In the existing literature, PLL is mostly applied to the linear analysis of the small-signal model, but for the nonlinear systems, a large deviation from the small-signal linear model is neglected in the case of large signal input $[16,17]$. Therefore, it is essential to conduct a nonlinear analysis of PLL. There are few studies on higher-order nonlinear systems. In the literature [16-20], the stability of the system is judged by the convergence of the solution of differential equations, which provides a reference for the analysis of higher-order nonlinear systems. In view of the method proposed in reference [20], the innovation is that, firstly, the structure of linear Kalman filter PLL with second-order generalized integrator is proposed, the state equation of the system is derived, and then the stability region is obtained by solving the state equation. Secondly, the second-order generalized integrators with different structures mentioned in the literature are applied to SSLKF and compared. Different phase-locked results are obtained under different input voltage conditions, important conclusions are drawn, and the application occasions of the second-order generalized integrators applied to SSLKF are pointed out under three different aviation variable frequency power supply conditions.

\section{Structure of the Linear Kalman Filter PLL with SOGI in the Microgrid}

In the present work, the linear Kalman filter PLL is adopted, and SOGI is added to the microgrid. The central angular frequency of the SOGI is output by the Kalman filter PLL obtained by feedback. Figure 1 displays the structure of PLL $[21,22]$.

2.1. Structure of the Linear Kalman Filter PLL. The structure of the Kalman filter PLL is given in reference [8], as shown in Figure 2.

The time-domain equation between the phase angle $\theta_{g}$ output by the Kalman filter PLL as well as the angular frequency $\omega_{g}$ and the three-phase grid voltages $v_{a}, v_{b}$, and $v_{c}$ after synchronous coordinate transformation can be expressed as follows:

$$
\left\{\begin{array}{l}
\omega_{g}=\int\left(k_{2} v_{q}+\int k_{1} v_{q} \mathrm{~d} t\right) \mathrm{d} t \\
\theta_{g}=\int\left(\omega_{g}+k_{3} v_{q}-\frac{T_{s}}{2} \int k_{1} v_{q} \mathrm{~d} t\right) \mathrm{d} t
\end{array}\right.
$$

where $k_{1}, k_{2}$, and $k_{3}$ are coefficients and $T_{s}$ denotes the sampling period.

\subsection{SOGIs of Three Structures}

2.2.1. Structure of A-Type SOGI. Figure 3 reveals the structure of A-type SOGI, where the central angular frequency is fed back by the angular frequency $\omega_{g}$ of the Kalman filter PLL $[23,24]$. The time-domain equation of A-type SOGI can be written as follows.where $k$ represents the damping coefficient of the SOGI and $q$ refers to the $q$ axis in the $d q$ coordinate system. 


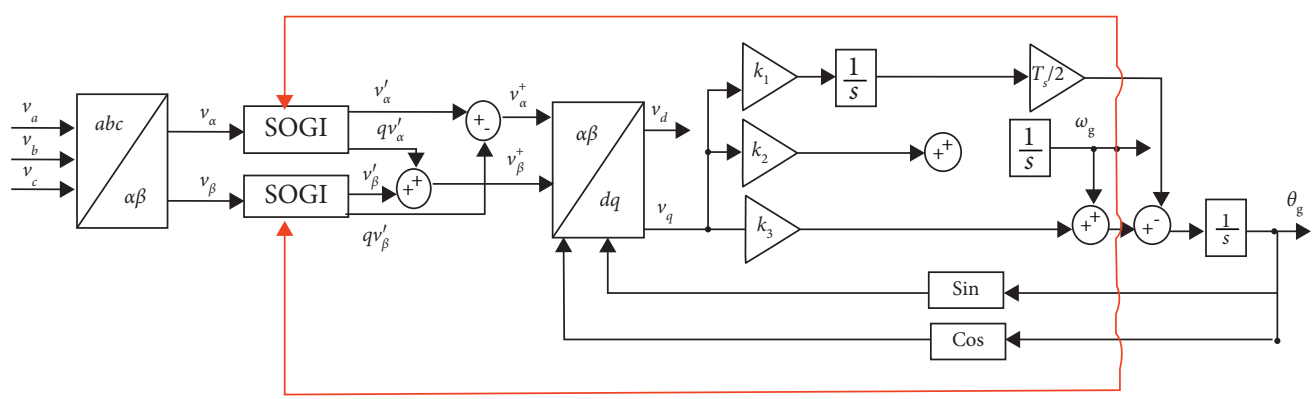

Figure 1: Structure of PLL.

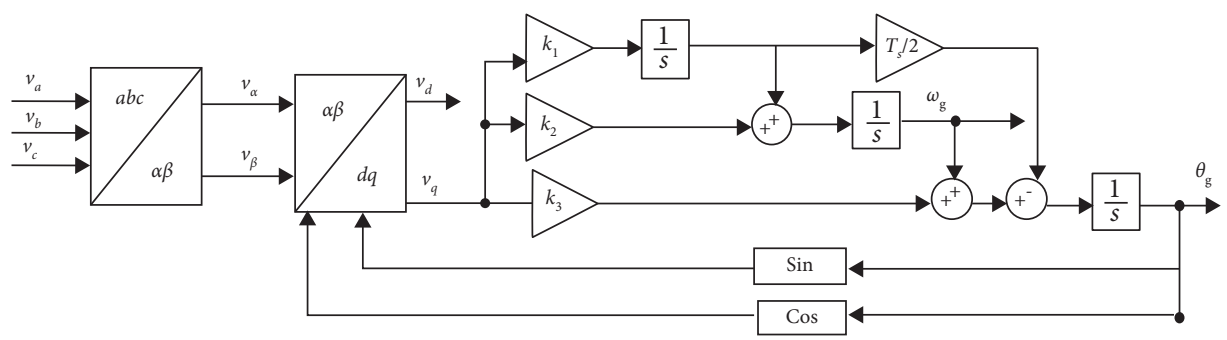

FIgURe 2: Structure of the Kalman filter PLL.

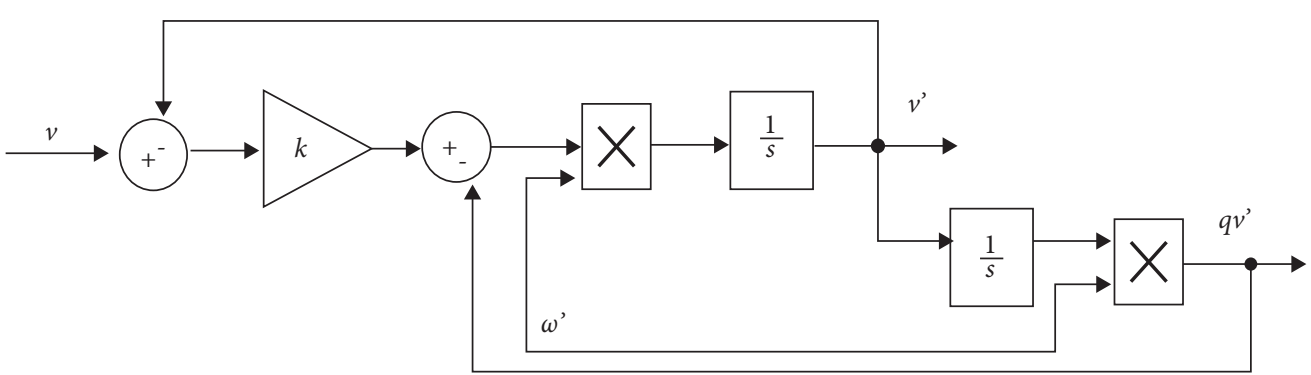

Figure 3: Structure of A-type SOGI.

$$
\left\{\begin{aligned}
v^{\prime} & =\int\left[\left(v-v^{\prime}\right) k-q v^{\prime}\right] \omega^{\prime} \mathrm{d} t \\
q v^{\prime} & =\omega^{\prime} \int v^{\prime} \mathrm{d} t \\
\omega^{\prime} & =\omega_{g}
\end{aligned}\right.
$$

2.2.2. Structure of B-Type SOGI. Figure 4 indicates the structure of B-type SOGI, where the central angular frequency is fed back by the angular frequency $\omega_{g}$ of the Kalman filter PLL [25]. The time-domain equation of B-type SOGI is shown in the following equation.

$$
\left\{\begin{aligned}
v^{\prime} & =\int\left[\left(v-v^{\prime}\right) k-q v^{\prime}\right] \omega^{\prime} \mathrm{d} t, \\
q v^{\prime} & =\int \omega^{\prime} v^{\prime} \mathrm{d} t, \\
\omega^{\prime} & =\omega_{g} .
\end{aligned}\right.
$$

Comparing equations (2) and (3), when the central angular frequency is fixed, the structures of A-type SOGI and B-type SOGI are the same. However, the research condition reported here is frequency conversion, so the structures of A-type SOGI and B-type SOGI are different.

2.2.3. Structure of C-Type SOGI. In reference [15], a C-type SOGI is proposed, as shown in Figure 5, where the central angular frequency is fed back by the angular frequency $\omega_{g}$ of the Kalman filter PLL. The time-domain equation of C-type SOGI is shown in the following equation.

$$
\left\{\begin{aligned}
v^{\prime} & =\int\left[\left(v-v^{\prime}\right) k-\int v^{\prime} \omega^{\prime} \mathrm{d} t\right] \omega^{\prime} \mathrm{d} t \\
q v^{\prime} & =\int \omega^{\prime} v^{\prime} \mathrm{d} t-k\left(v-v^{\prime}\right) \\
\omega^{\prime} & =\omega_{g}
\end{aligned}\right.
$$




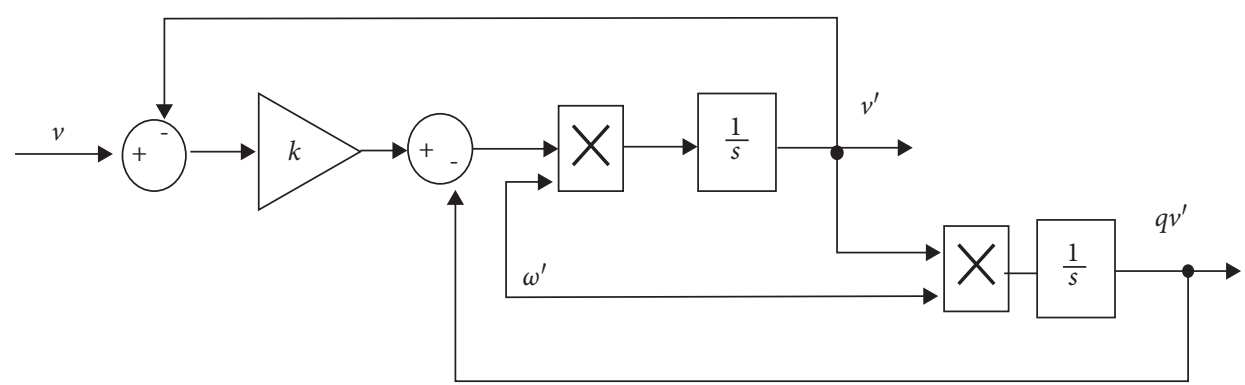

FIGURE 4: Structure of B-type SOGI.

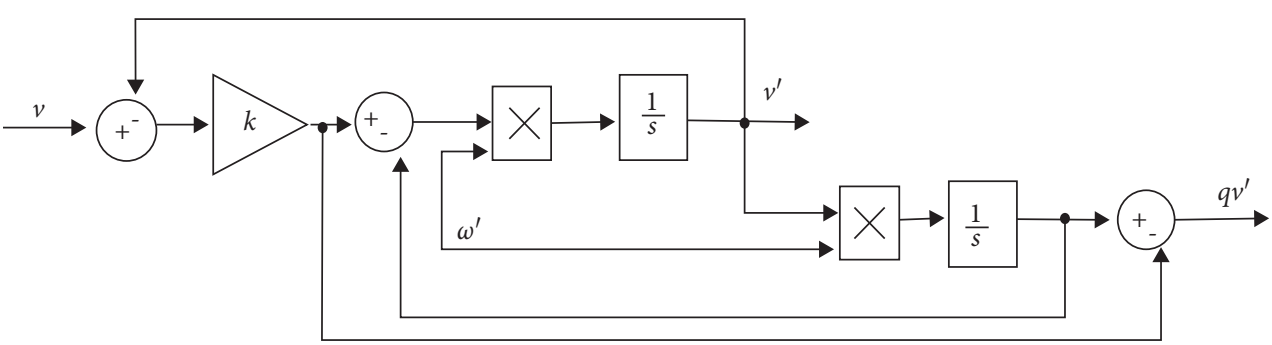

FIgURE 5: Structure of C-type SOGI.

\section{System Stability Analysis and Parameter Design}

According to the system chart in Figure 1, the real-time angular frequency output by the microgrid system is fed back to the SOGI. Since the frequency of the aviation variable frequency power supply changes in real time, the whole system forms a high-order nonlinear structure.

$v_{\alpha}$ and $v_{\beta}$ are the linear transformations of three-phase input voltages $v_{a}, v_{b}$, and $v_{c}$, so they can be regarded as the input of the system. When SOGI in Figure 1 is an A-type SOGI, from Figure 1 and equation (2), there are

$$
\begin{aligned}
v_{\alpha}^{\prime} & =\int\left[k\left(v_{\alpha}-v_{\alpha}^{\prime}\right)-q v_{\alpha}^{\prime}\right] \omega_{g} \mathrm{~d} t, \\
q v_{\alpha}^{\prime} & =\omega_{g} \int v_{\alpha}^{\prime} \mathrm{d} t, \\
v_{\beta}^{\prime} & =\int\left[k\left(v_{\beta}-v_{\beta}^{\prime}\right)-q v_{\beta}^{\prime}\right] \omega_{g} \mathrm{~d} t, \\
q v_{\beta}^{\prime} & =\omega_{g} \int v_{\beta}^{\prime} \mathrm{d} t .
\end{aligned}
$$

According to the transformation formula from $\alpha \beta$ axis to $d q$ axis, the relationship between the output phase angle of the microgrid system and each quantity can be presented by

$$
v_{q}=\left(v_{\beta}^{\prime}+q v_{\alpha}^{\prime}\right) \cos \theta_{g}-\left(v_{\alpha}^{\prime}-q v_{\beta}^{\prime}\right) \sin \theta_{g} .
$$

Therefore, according to equations (1) and (5)-(9), the time-domain equation of the whole system combining SSLKF with A-type SOGI can be expressed as follows:

$$
\left\{\begin{array}{l}
v_{\alpha}^{\prime}=\int\left[k\left(v_{\alpha}-v_{\alpha}^{\prime}\right)-q v_{\alpha}^{\prime}\right] \omega_{g} \mathrm{~d} t, \\
q v_{\alpha}^{\prime}=\omega_{g} \int v_{\alpha}^{\prime} \mathrm{d} t, \\
v_{\beta}^{\prime}=\int\left[k\left(v_{\beta}-v_{\beta}^{\prime}\right)-q v_{\beta}^{\prime}\right] \omega_{g} \mathrm{~d} t, \\
q v_{\beta}^{\prime}=\omega_{g} \int v_{\beta}^{\prime} \mathrm{d} t, \\
v_{q}=\left(v_{\beta}^{\prime}+q v_{\alpha}^{\prime}\right) \cos \theta_{g}-\left(v_{\alpha}^{\prime}-q v_{\beta}^{\prime}\right) \sin \theta_{g}, \\
\omega_{g}=\int\left(k_{2} v_{q}+\int k_{1} v_{q} \mathrm{~d} t\right) \mathrm{d} t, \\
\theta_{g}=\int\left(\omega_{g}+k_{3} v_{q}-\frac{T_{s}}{2} \int k_{1} v_{q} \mathrm{~d} t\right) \mathrm{d} t .
\end{array}\right.
$$


State variables are selected as follows:

$$
\left\{\begin{array}{l}
x_{p 1}=v_{\alpha}^{\prime}, \\
x_{p 2}=\frac{q v_{\alpha}^{\prime}}{\omega_{g}}, \\
x_{p 3}=v_{\beta}^{\prime}, \\
x_{p 4}=\frac{q v_{\beta}^{\prime}}{\omega_{g}}, \\
x_{p 5}=\int v_{q} \mathrm{~d} t, \\
x_{p 6}=\omega_{g}, \\
x_{p 7}=\theta_{g} .
\end{array}\right.
$$

Equation (12) is an equation of the state of equation (10).

$$
\left\{\begin{array}{l}
\dot{x}_{p 1}=k v_{\alpha} x_{p 6}-k x_{p 1} x_{p 6}-x_{p 2} x_{p 6}^{2} \\
\dot{x}_{p 2}=x_{p 1}, \\
\dot{x}_{p 3}=k v_{\beta} x_{p 6}-k x_{p 3} x_{p 6}-x_{p 4} x_{p 6}^{2} \\
\dot{x}_{p 4}=x_{p 3}, \\
\dot{x}_{p 5}=\left(x_{p 3}+x_{p 2} x_{p 6}\right) \cos x_{p 7}-\left(x_{p 1}-x_{p 4} x_{p 6}\right) \sin x_{p 7}, \\
\dot{x}_{p 6}=k_{2}\left(x_{p 3}+x_{p 2} x_{p 6}\right) \cos x_{p 7}-k_{2}\left(x_{p 1}-x_{p 4} x_{p 6}\right) \sin x_{p 7} \\
+k_{1} x_{p 5}, \\
\dot{x}_{p 7}=x_{p 6}+k_{3}\left(x_{p 3}+x_{p 2} x_{p 6}\right) \cos x_{p 7} \\
-k_{3}\left(x_{p 1}-x_{p 4} x_{p 6}\right) \sin x_{p 7}-\frac{T s}{2} k_{1} x_{p 5} .
\end{array}\right.
$$

Similarly, the time-domain equation of the whole system integrating SSLKF and B-type SOGI is shown in equation (13), and the equation of that combining SSLKF and C-type SOGI is written as equation (14).

$$
\left\{\begin{aligned}
& v_{\alpha}^{\prime}=\int\left[k\left(v_{\alpha}-v_{\alpha}^{\prime}\right)-q v_{\alpha}^{\prime}\right] \omega_{g} \mathrm{~d} t, \\
& q v_{\alpha}^{\prime}=\int \omega_{g} v_{\alpha}^{\prime} \mathrm{d} t, \\
& v_{\beta}^{\prime}=\int\left[k\left(v_{\beta}-v_{\beta}^{\prime}\right)-q v_{\beta}^{\prime}\right] \omega_{g} \mathrm{~d} t, \\
& q v_{\beta}^{\prime}=\int \omega_{g} v_{\beta}^{\prime} \mathrm{d} t, \\
& v_{q}=\left(v_{\beta}^{\prime}+q v_{\alpha}^{\prime}\right) \cos \theta_{g}-\left(v_{\alpha}^{\prime}-q v_{\beta}^{\prime}\right) \sin \theta_{g}, \\
& \theta_{g}\left.=\int\left(\omega_{g}+k_{3} v_{q}-\frac{T_{s}}{2}\right] k_{1} v_{q} \mathrm{~d} t\right) \mathrm{d} t . \\
& \omega_{g}=\int\left(k_{2} v_{q}+\int k_{1} v_{q} \mathrm{~d} t\right) \mathrm{d} t, \\
&\left.\omega_{q} v_{q}+\int k_{1} v_{q} \mathrm{~d} t\right) \mathrm{d} t,=\int\left[v_{\beta}^{\prime}+q v_{\alpha}^{\prime}\right) \cos \theta_{g}-\left(v_{\alpha}^{\prime}-q v_{\beta}^{\prime}\right) \sin \theta_{g}, \\
& v_{\beta}^{\prime}=\int \omega_{g} v_{\alpha}^{\prime} \mathrm{d} t-k\left(v_{\alpha}-v_{\alpha}^{\prime}\right), \\
& \theta_{g}^{\prime}=\int\left(\omega_{g}+k_{3} v_{q}-\frac{T_{s}}{2} \int k_{1} v_{q} \mathrm{~d} t\right) \mathrm{d} t, \\
&\left\{\begin{array}{l}
\left.v_{\alpha}\left(v_{\alpha}-v_{\alpha}^{\prime}\right)-\int \omega_{g} v_{\alpha}^{\prime} \mathrm{d} t\right] \omega_{g} \mathrm{~d} t, \\
\left.v_{\beta} \mathrm{d} t\right] \omega_{g} \mathrm{~d} t,
\end{array}\right.
\end{aligned}\right.
$$

For equations (13) and (14), the following state variables are selected: 


$$
\begin{aligned}
& \left\{\begin{array}{l}
x_{o 1}=v_{\alpha}^{\prime}, \\
x_{o 2}=q v_{\alpha}^{\prime}, \\
x_{o 3}=v_{\beta}^{\prime}, \\
x_{o 4}=q v_{\beta}^{\prime}, \\
x_{o 5}=\int v_{q} \mathrm{~d} t, \\
x_{o 6}=\omega_{g}, \\
x_{o 7}=\theta_{g},
\end{array}\right. \\
& \left\{\begin{array}{l}
x_{r 1}=v_{\alpha}^{\prime}, \\
x_{r 2}=q v_{\alpha}^{\prime}, \\
x_{r 3}=v_{\beta}^{\prime}, \\
x_{r 4}=q v_{\beta}^{\prime}, \\
x_{r 5}=\int v_{q} \mathrm{dt}, \\
x_{r 6}=\omega_{g}, \\
x_{r 7}=\theta_{g} .
\end{array}\right.
\end{aligned}
$$

Then, equations (13) and (14) are written as equations of state as shown in equations (17) and (18).

$$
\left\{\begin{array}{l}
\dot{x}_{o 1}=k v_{\alpha} x_{o 6}-k x_{o 1} x_{o 6}-x_{o 2} x_{o 6}, \\
\dot{x}_{o 2}=x_{o 1} x_{o 6}, \\
\dot{x}_{o 3}=k v_{\beta} x_{o 6}-k x_{o 3} x_{o 6}-x_{o 4} x_{o 6} \\
\dot{x}_{o 4}=x_{o 3} x_{o 6}, \\
\dot{x}_{o 5}=\left(x_{o 3}+x_{o 2}\right) \cos x_{o 7}-\left(x_{o 1}-x_{o 4}\right) \sin x_{o 7}, \\
\dot{x}_{o 6}=k_{2}\left(x_{o 3}+x_{o 2}\right) \cos x_{o 7}-k_{2}\left(x_{o 1}-x_{o 4}\right) \sin x_{o 7}+k_{1} x_{o 5}, \\
\dot{x}_{o 7}=x_{o 6}+k_{3}\left(x_{o 3}+x_{o 2}\right) \cos x_{o 7}-k_{3}\left(x_{o 1}-x_{o 4}\right) \sin x_{o 7} \\
-\frac{T_{s}}{2} k_{1} x_{o 5}
\end{array}\right.
$$

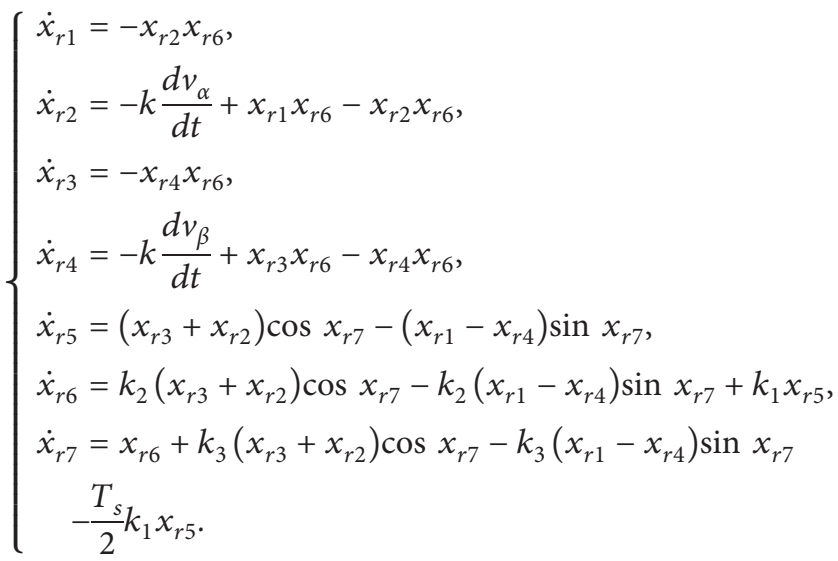

According to equations (12), (17), and (18), this system is a seventh-order nonlinear system, and the stability of the system is determined by the parameters $k, k_{1}, k_{2}, k_{3}$, and $T_{s}$. Hence, it is essential to first determine the value of $k_{1}, k_{2}, k_{3}$, and $T_{s}$ to select the bandwidth of the Kalman filter PLL. After this procedure, the stability of the system only depends on the value of $k$.

Reference [8] provides the small-signal processing model of the intelligent sensor for the linear Kalman filter PLL, as shown in Figure 6. Equation (19) describes the closed-loop transfer function of the linear Kalman filter PLL.

$$
G(s)=\frac{\widetilde{\omega}_{g}(s)}{\omega_{g}(s)}=\frac{k_{2} s+k_{1}}{s^{3}+k_{3} s^{2}+k_{2} s+k_{1}} .
$$

To ensure the stability of the linear Kalman filter PLL, the roots of the characteristic equation of its closed-loop transfer function are set as a negative real root and a pair of negative real part conjugate roots:

$$
\begin{aligned}
s_{0} & =-w_{n} R, \\
s_{1,2} & =-w_{n} \operatorname{Exp}( \pm j \phi),
\end{aligned}
$$

where $w_{n}>0, R>0$, and $0<\phi<\pi / 2$.

Substitute equation (20) into the characteristic equation, and there is

$$
\begin{aligned}
& k_{1}=R w_{n}^{3}, \\
& k_{2}=(1+2 R \cos \phi) w_{n}^{2}, \\
& k_{3}=(R+2 \cos \phi) w_{n} .
\end{aligned}
$$

Substituting equation (21) into equation (19), equation (19) can be written as follows:

$$
G(s)=\frac{(1+2 R \cos \phi) w_{n}^{2} s+R w_{n}^{3}}{s^{3}+(R+2 \cos \phi) w_{n} s^{2}+(1+2 R \cos \phi) w_{n}^{2} s+R w_{n}^{3}} .
$$

The bandwidth $f_{b}$ of the linear Kalman filter PLL is decided by the parameters $R, w_{n}$, and $\phi[26-28]$.

According to the definition of bandwidth, there is

$$
20 \lg \left|G\left(j 2 \pi f_{b}\right)\right|=20 \lg |G(j 0)|-20 \lg \sqrt{2} \text {. }
$$

Then, the relation between bandwidth and each parameter can be presented as follows:

$\frac{w_{n}^{2} \sqrt{R^{2} w_{n}^{2}+(2 R \cos \phi+1)^{2}\left(2 \pi f_{b}\right)^{2}}}{\sqrt{\left(\left(2 \pi f_{b}\right)^{2}-w_{n}^{2}\right)^{2}+4 w_{n}^{2} \cos ^{2} \phi\left(2 \pi f_{b}\right)^{2}} \sqrt{R^{2} w_{n}^{2}+\left(2 \pi f_{b}\right)^{2}}}=\frac{1}{\sqrt{2}}$.

According to the literature [7], the change in parameter $w_{n}$ has a significant influence on the bandwidth. Therefore, let $R=1$ and $\phi=\pi / 3$, and $f_{b}$ is determined by the parameter $w_{n}$. The bandwidth is set to $100 \mathrm{~Hz}, 200 \mathrm{~Hz}$, and $300 \mathrm{~Hz}$, respectively, and the values of parameter $w_{n}$ are summarized in Table 1.

Firstly, the bandwidth of the linear Kalman filter PLL is selected. By adding the A-type SOGI, the filtering 


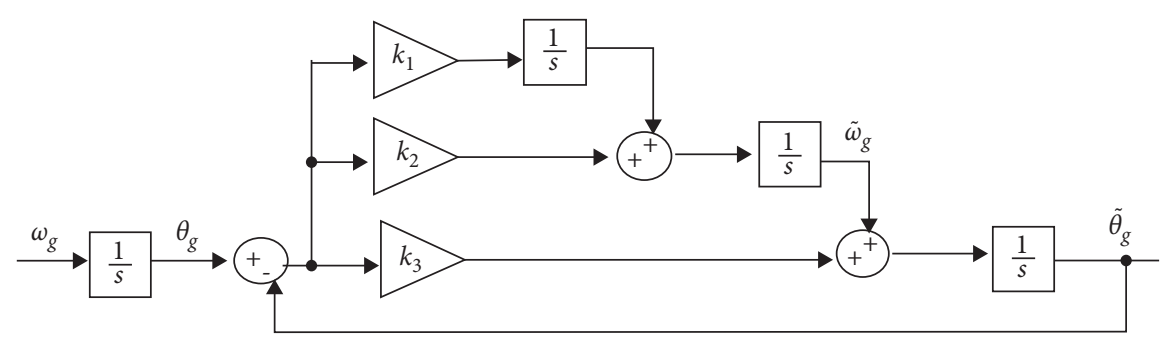

Figure 6: Small-signal model of the linear Kalman filter PLL.

TABLE 1: Values of $w_{n}$ at different bandwidths.

\begin{tabular}{lccc}
\hline$R=1 \phi=\pi / 3$ & $f_{b}=100 \mathrm{~Hz}$ & $f_{b}=200 \mathrm{~Hz}$ & $f_{b}=300 \mathrm{~Hz}$ \\
\hline$w_{n}$ & 369.478 & 738.955 & 1108.433 \\
\hline
\end{tabular}

performance and dynamic performance of the linear Kalman filter PLL under three different bandwidths are compared, to select the appropriate Kalman filter phase-locked parameters.

In the three-phase balanced microgrid system, A-phase voltage can be expressed as follows:

$$
\begin{aligned}
v_{a}= & 115 \sqrt{2} \cos \omega t+15 \cos \left(5 \omega t+18^{\circ}\right) \\
& +8 \cos \left(7 \omega t+15^{\circ}\right)+5 \cos \left(11 \omega t+12^{\circ}\right) .
\end{aligned}
$$

The fundamental frequency is set to $400 \mathrm{~Hz}$, the fundamental voltage of $v_{a}$ is denoted as $v_{a f u n d}$, and the effective value is $115 \mathrm{~V}$. Besides, the total voltage distortion rate is $10.8 \%$, the maximum single voltage distortion rate is $9.2 \%$, and the parameter $k$ of A-type SOGI is 1 . Then, the simulation results of the linear Kalman filter PLL under the above three bandwidths are compared.

As shown in Figure 7, the angular frequency $\omega_{g}$ output by the PLL attains a steady-state value of $800 \pi \mathrm{rad} / \mathrm{s}$ in all three bandwidths. Moreover, the dynamic response of bandwidth at $300 \mathrm{~Hz}$ is better, but the oscillation time before entering a steady state is longer. The bandwidth at $100 \mathrm{~Hz}$ has the slowest dynamic response.

As shown in Figure 8, the PLL output $\cos \theta_{g}$ enlarged 100 times is compared with $v_{a}$ and $v_{a f u n d}$. Under these three bandwidths, the voltage amplitudes of $\cos \theta_{g}, v_{a}, v_{a f u n d}$ remain unchanged with the increase of bandwidth. The voltage amplitude of $\cos \theta_{g}$ is maintained at about $100 \mathrm{~V}$, the vibration period has no change trend with the expansion of band width multiple, the time required for the period is $0.0025 \mathrm{~s}$, and the phase-locked accuracy is high. THD of $\cos \theta_{g}$ of PLL output under the three bandwidths is $0.97 \%$, $0.98 \%$, and $1.01 \%$, respectively, which have good filtering effect.

Considering the dynamic response and filtering effect of the PLL, the bandwidth of the linear Kalman filter PLL is set to $200 \mathrm{~Hz}$. Correspondingly, the parameters are $R=1$, $\phi=\pi / 3$, and $w_{n}=738.955$.

According to equation (13), $k_{1}=738.955^{3}$, $k_{2}=1,092,108.98,405$, and $k_{3}=1,477.91$.

In [29], the solution of differential equations is used to judge the stability of the microgrid system. Since the stability of the system is independent of the input, let $v_{\alpha}$ be $1 \mathrm{~V}, v_{\alpha}$ be
$1 \mathrm{~V}$, and sampling period $T_{s}$ be $0.000,125 \mathrm{~s}$. The Ode23tb function in Matlab is used to solve the solution of differential equations.

Figure 9 presents the solutions of the differential equations under different values of parameter $k$ of A-type SOGI.

Figure 10 provides the solutions of the differential equations when parameter $k$ of B-type SOGI has different values.

Figure 11 indicates the solutions of differential equations when parameter $k$ of C-type SOGI has different values.

From Figures 9-11, when $k=0.5, k=1, k=2, k=3$, and $k=5, x_{1} \sim x_{6}$ converge over time, while $x_{7}$ diverges. However, $x_{7}=\theta_{g}$, and it is a time-dependent variable, and $x_{5}=0$. Besides, $v_{q}$ is a bounded quantity, as well as a margin of error, so the system is stable. It can be seen from Figure 10 that the transformation of all state variables converges with time, so the microgrid system is stable. Since the stability region of the system is a sufficient condition for the stability of the system, a conservative stability region can be selected, and $k$ is stable at $[0.5,3]$. Thus, the damping coefficient $k$ of the three SOGIs is stable at $[0.5,3]$.

\section{Simulation and Experimental Verification}

The previous section concludes that the system parameters $k_{1}=738.955^{3}, \quad k_{2}=1,092,108.98,405, \quad k_{3}=1,477.91, \quad$ and $T_{s}=0.000,125 \mathrm{~s}$, and $k$ is stable within the range of $[0.5,3]$. Then, Simulink is adopted to conduct the comparative simulation of A-type, B-type, and C-type SOGIs combined with linear Kalman filter PLLs.

4.1. Voltage Containing Harmonics of the Aviation Frequency Conversion Power Supply. In the three-phase balanced microgrid system, the A-phase voltage is represented by equation (25), the total voltage distortion rate is $10.8 \%$, and the maximum single voltage distortion rate is $9.2 \%$. Moreover, the fundamental wave frequency is $360 \sim 800 \mathrm{~Hz}$, and the change rate is a linear change of $200 \mathrm{~Hz} / \mathrm{s}$ according to the standard of DO-160G.

When $k_{1}=738.955^{3}, k_{2}=1,092,108.98,405, k_{3}=1,477.91$, and $T_{s}=0.000,125 \mathrm{~s}$, the parameter $k$ of three kinds of SOGIs is 1 . Figure 12 illustrates the comparison of angular frequency and phase angle of the linear Kalman filter PLL without SOGI, PLL with A-type SOGI, PLL with B-type SOGI, and PLL with C-type SOGI. 


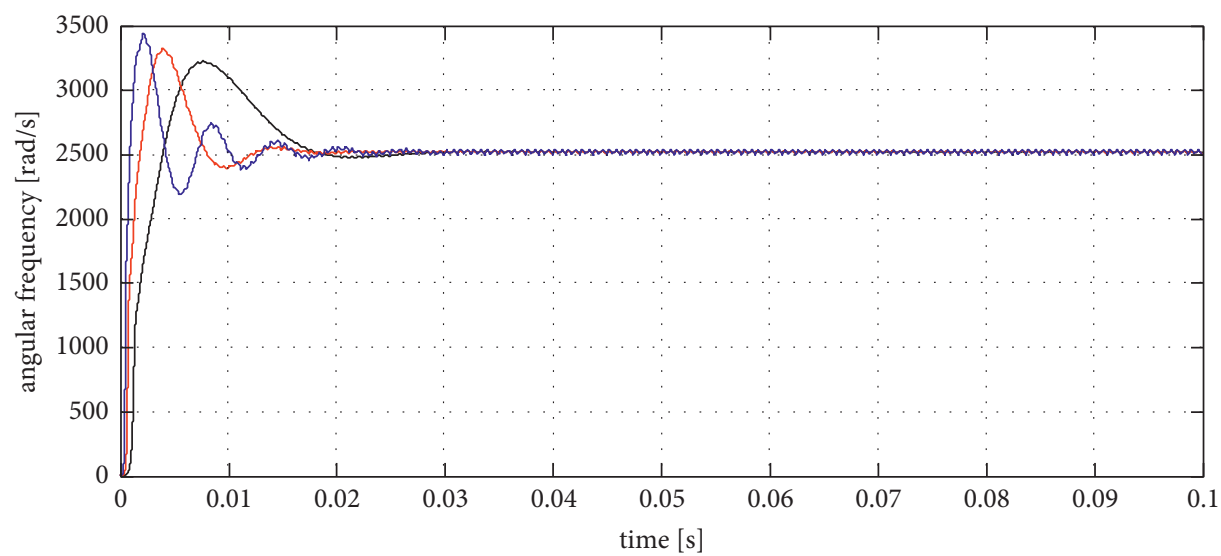

- $\mathrm{fb}=100 \mathrm{~Hz}$

- $\mathrm{fb}=200 \mathrm{~Hz}$

- $\mathrm{fb}=300 \mathrm{~Hz}$

FIGURE 7: Simulation results under three bandwidths.

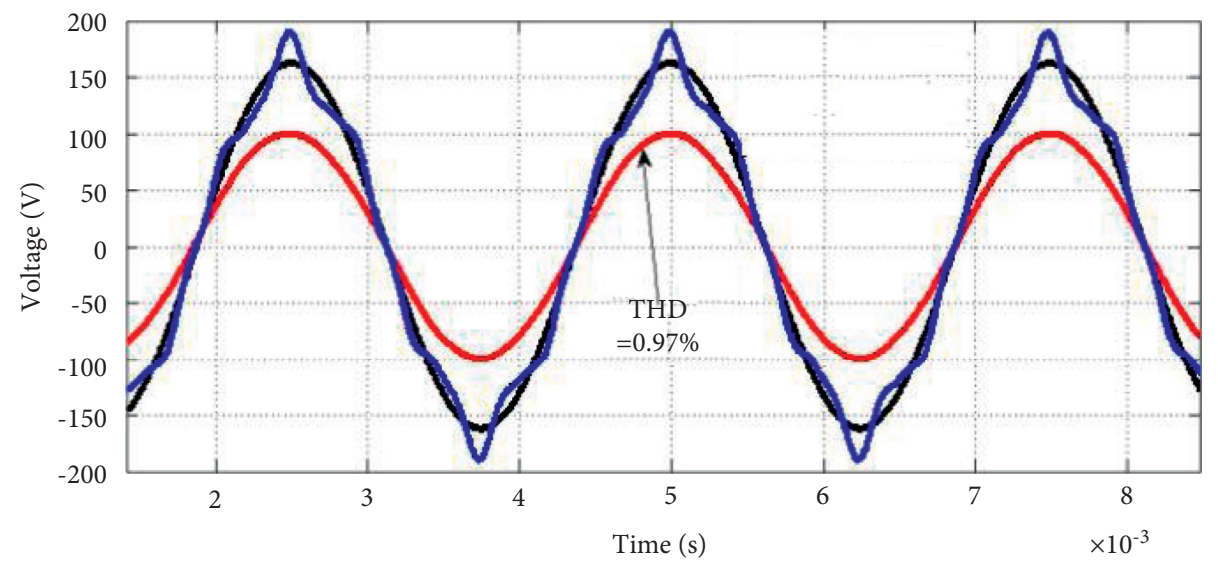

- Vafund
$-\quad 100 \cos \theta g$
Va

(a)

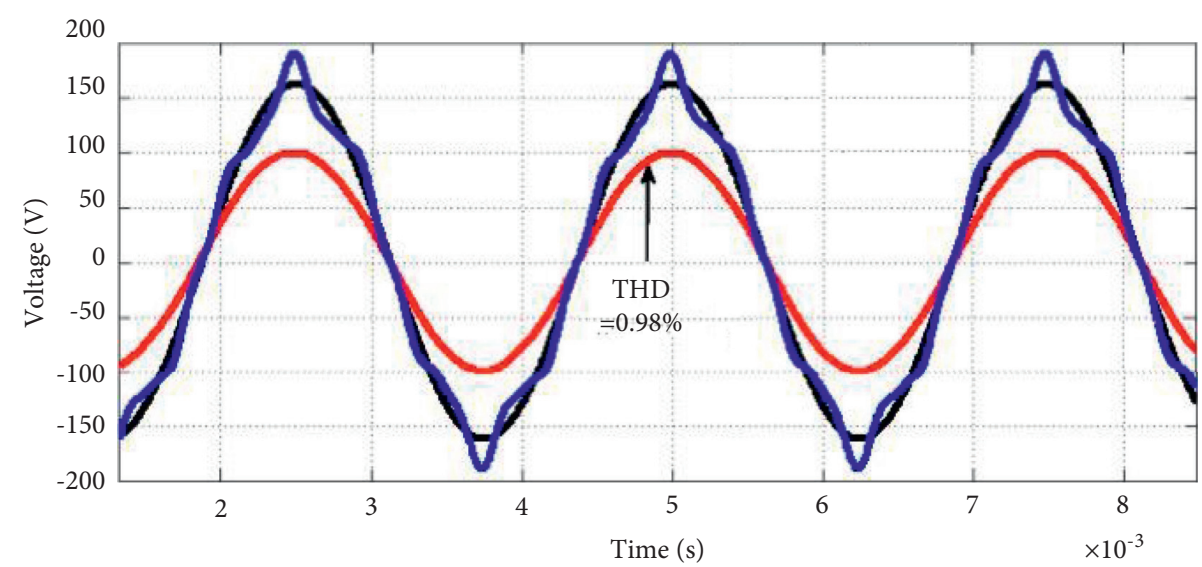

- Vafund
$-100 \cos \theta \mathrm{g}$
Va

(b)

FIGURE 8: Continued. 


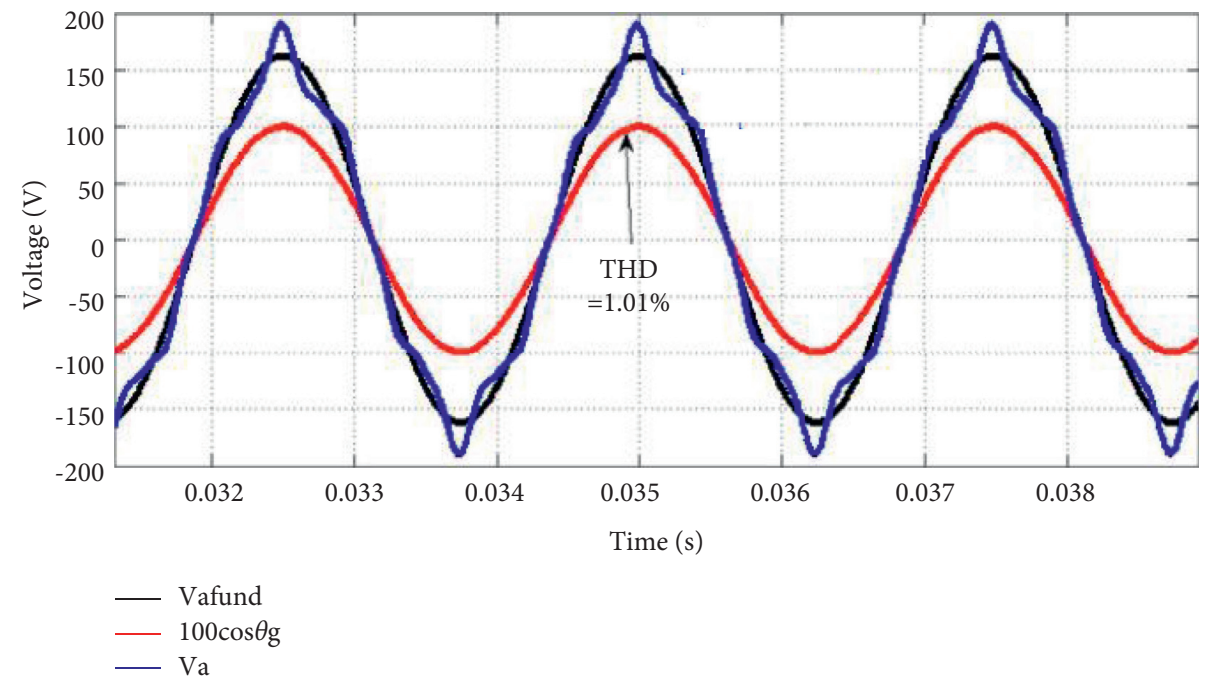

(c)

FIGURE 8: Simulation results of $\cos \theta_{g}$ under three bandwidths: (a) $f_{b}=100 \mathrm{~Hz}$; (b) $f_{b}=200 \mathrm{~Hz}$; (c) $f_{b}=300 \mathrm{~Hz}$.
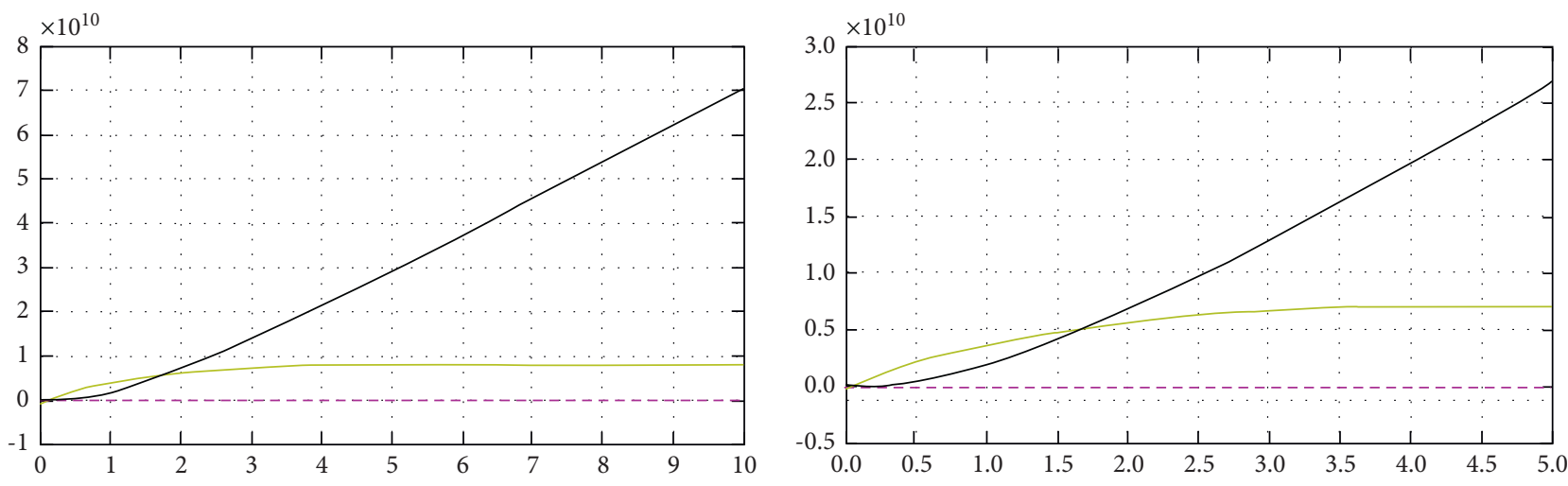

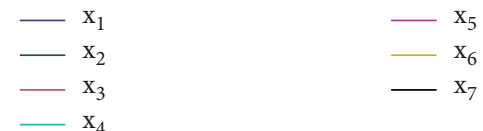

(a)
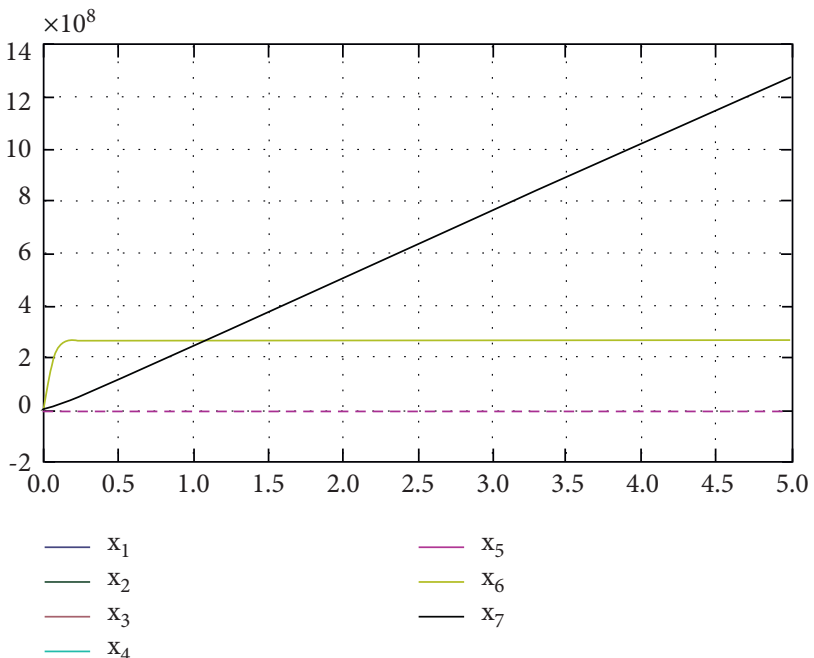

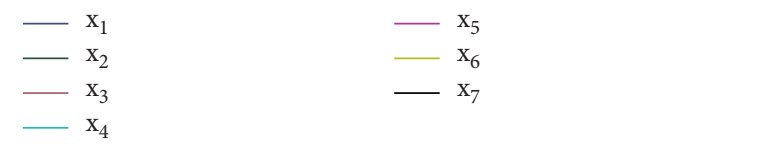

(b)
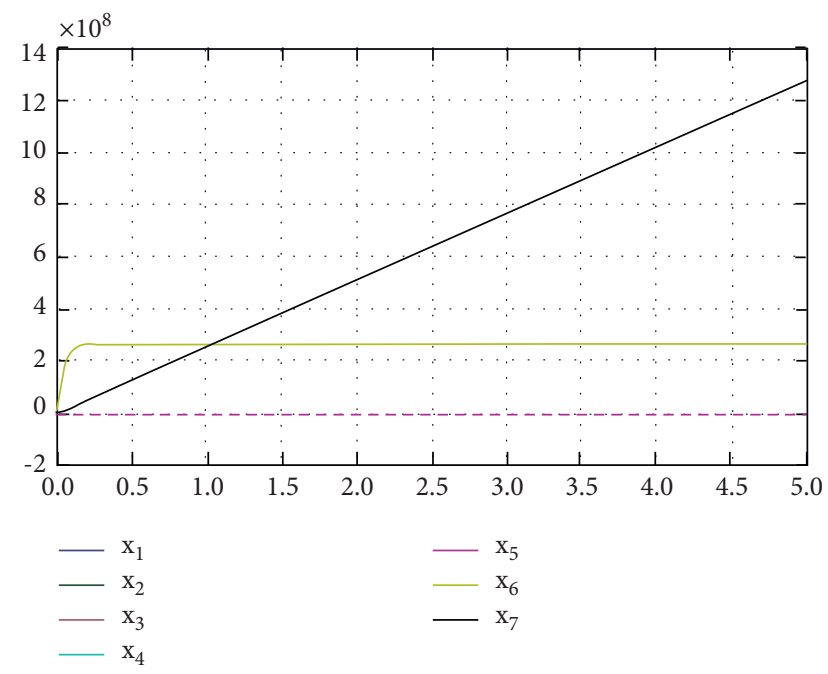

(d)

FIgure 9: Continued. 


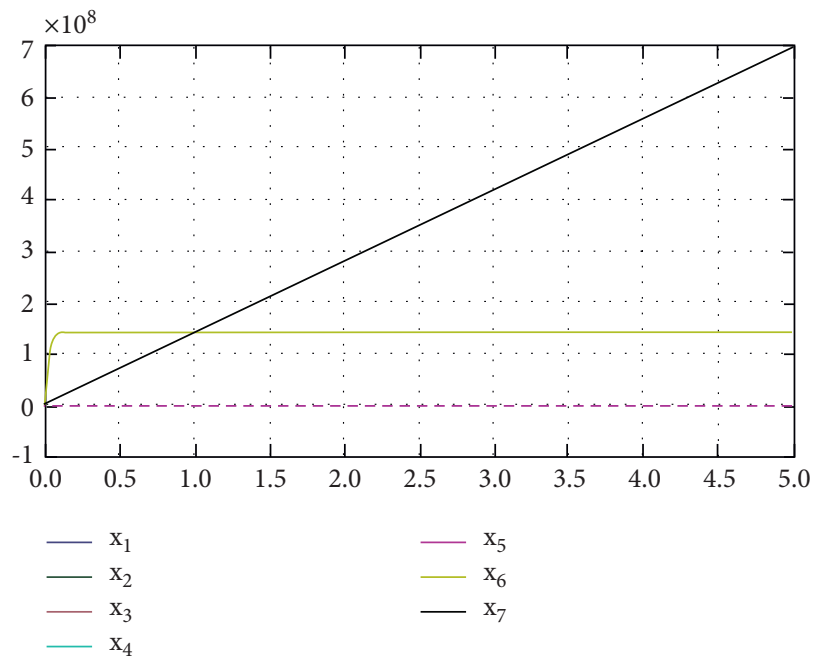

(e)

Figure 9: Solutions of A-type SOGI differential equations: (a) $k=0.5$; (b) $k=1$; (c) $k=2$; (d) $k=3$; (e) $k=5$.
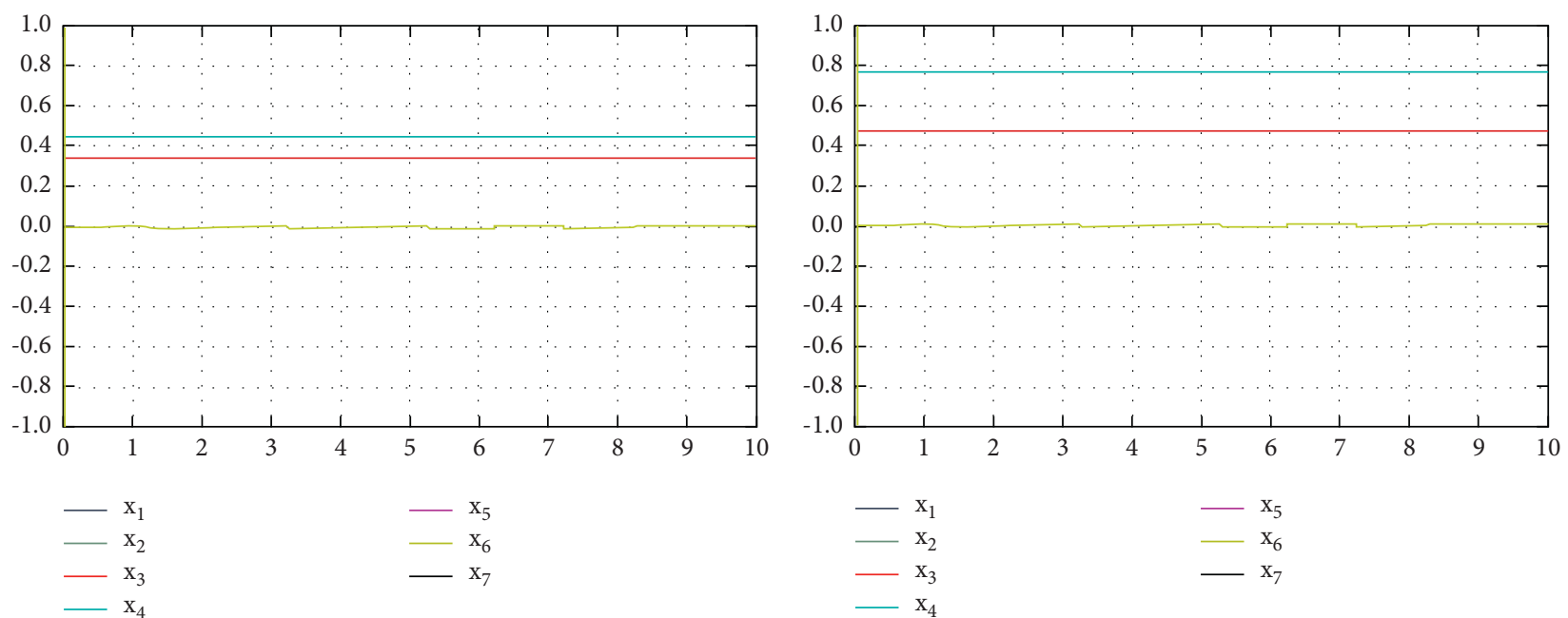

(a)

(b)
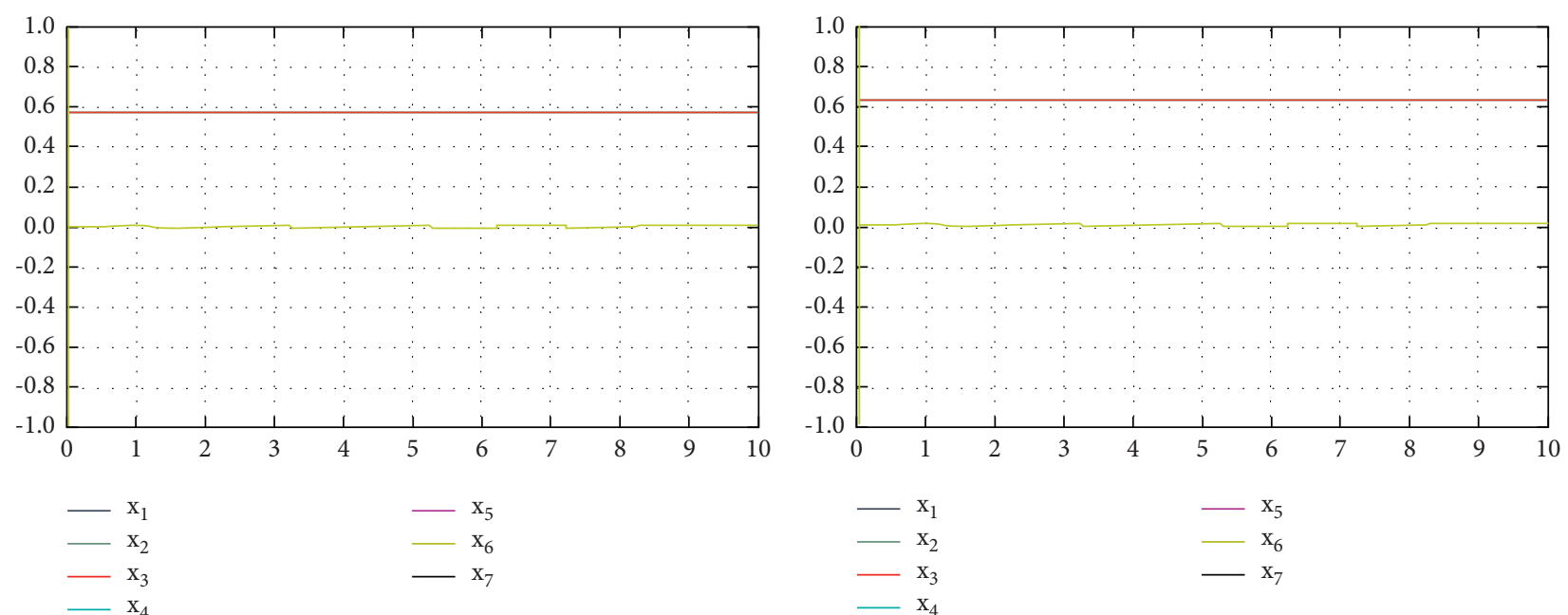

(c)

(d)

Figure 10: Continued. 


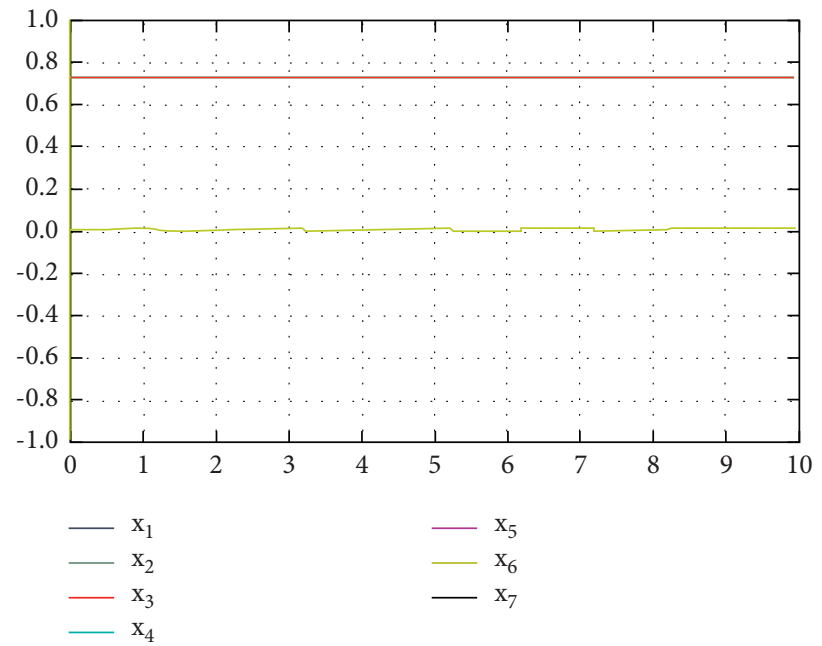

(e)

Figure 10: Solutions of the differential equations of B-type SOGI: (a) $k=0.5$; (b) $k=1$; (c) $k=2$; (d) $k=3$; (e) $k=5$.

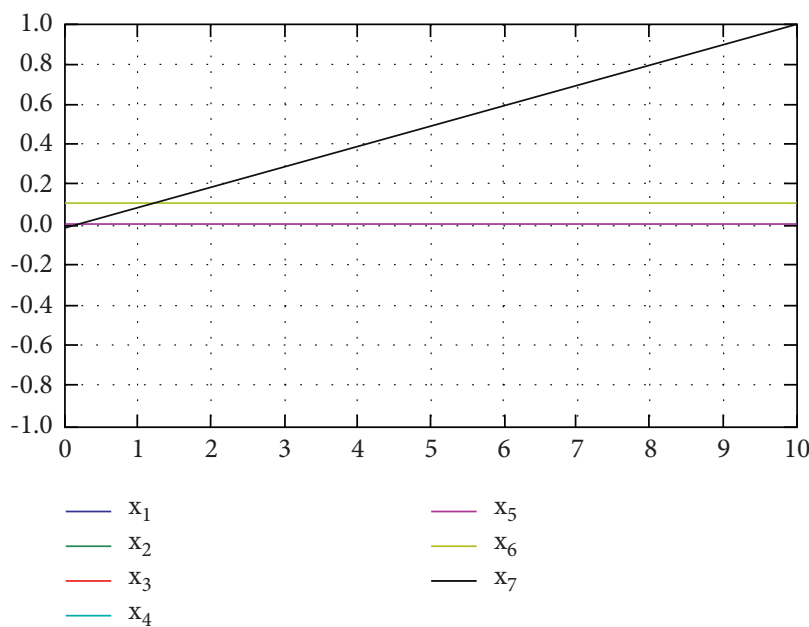

(a)

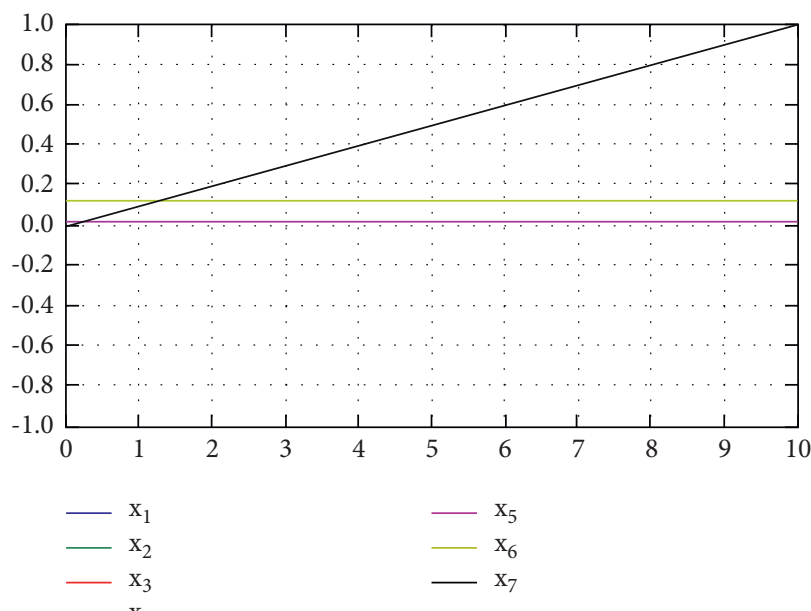

(c)

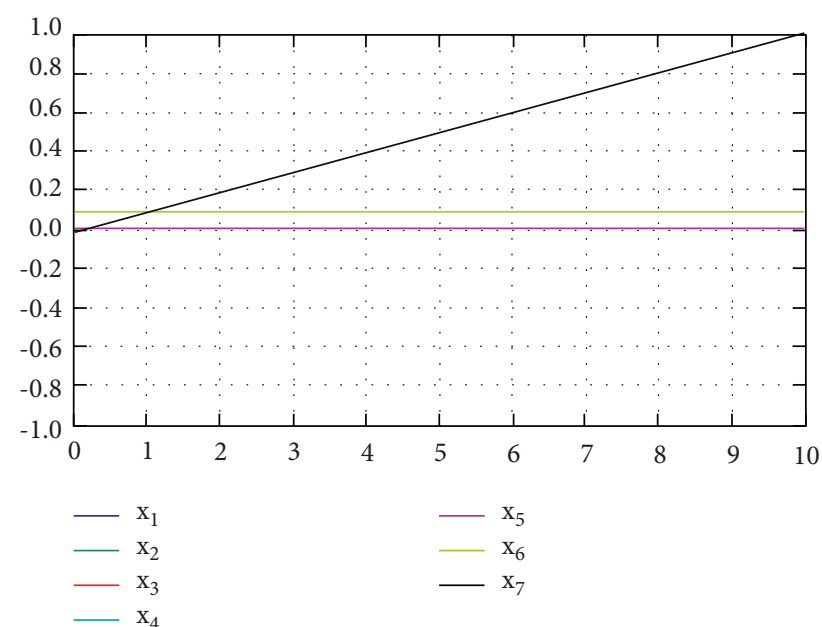

(b)

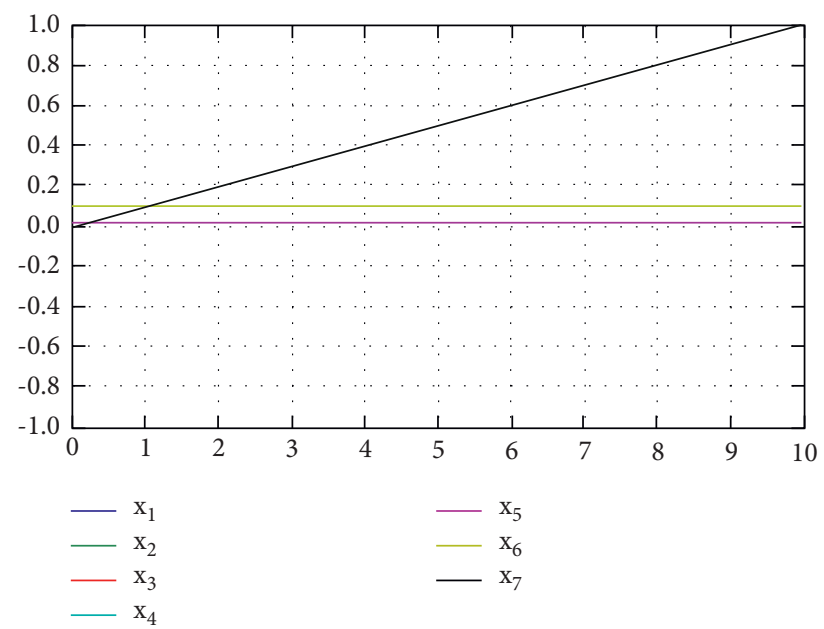

(d)

Figure 11: Continued. 


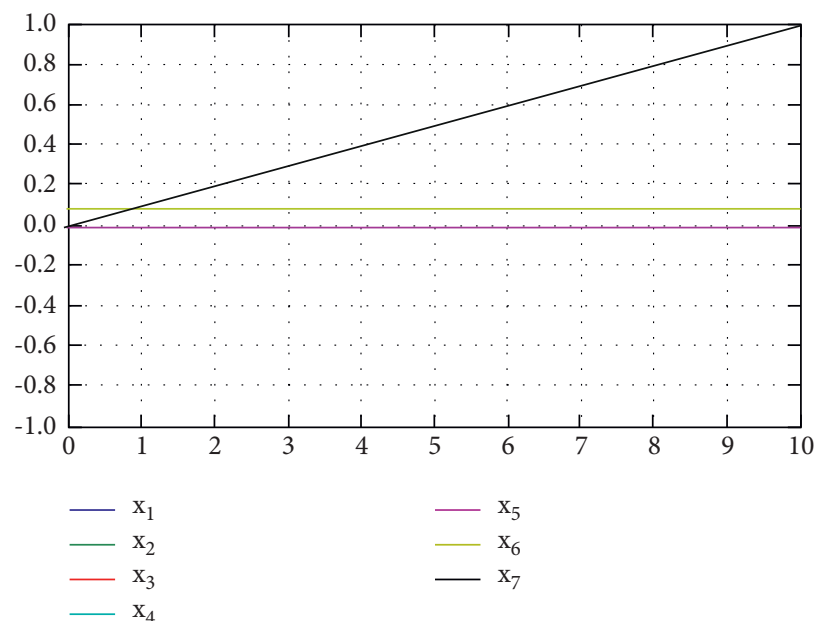

(e)

FIgURE 11: Solutions of the differential equations of C-type SOGI: (a) $k=0.5$; (b) $k=1$; (c) $k=2$; (d) $k=3$; (e) $k=5$.

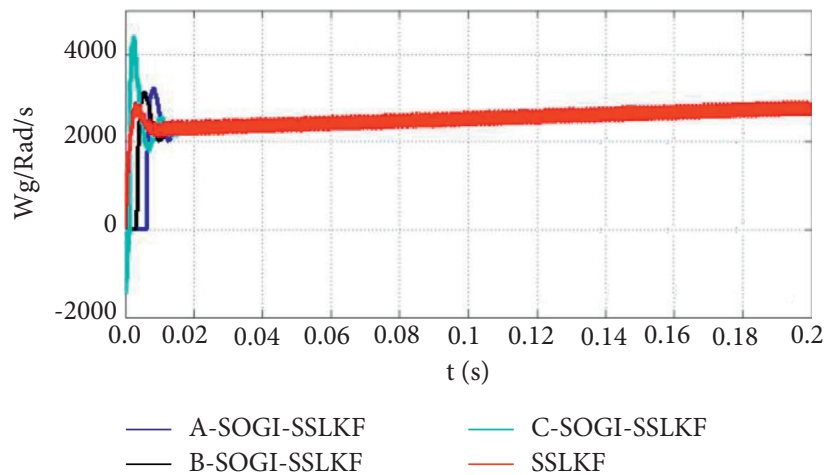

(a)

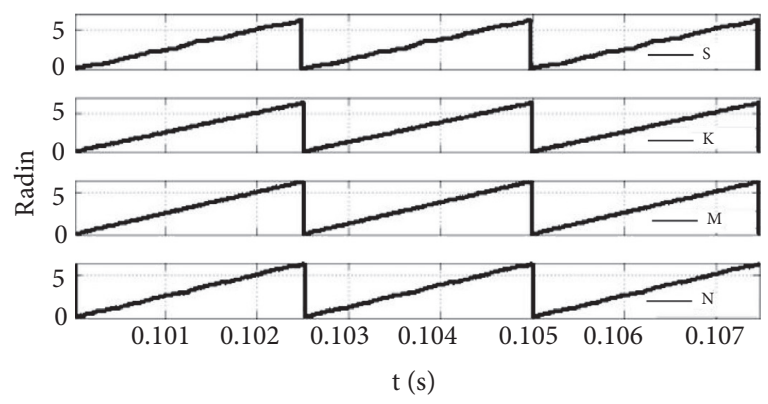

(b)

FIGURE 12: Simulation results of aviation frequency conversion power supply containing harmonics: (a) $\omega_{g}$; (b) $\theta_{g}$ (S represents SSLKF; K represents A-SOGI-SSLKF; M represents B-SOGI-SSLKF; N stands for C-SOGI-SSLKF).

Through Figure 12, the angular frequency $\omega_{g}$ output by the PLL ultimately changes linearly at a rate of $400 \pi \mathrm{rad} / \mathrm{s}^{2}$, and the phase angle $\theta_{g}$ also reaches a stable state. The PLLs with A-type SOGI and B-type SOGI achieve better linearity of the phase angle and a better restraining effect on the harmonic content of aviation frequency conversion power supply. In addition, the linear Kalman filter PLL with B type has better dynamic performance than that with A type.

\subsection{Three-Phase Voltage Imbalance of Aviation Frequency} Conversion Power Supply. The three-phase voltage is expressed as follows:

$$
\left\{\begin{array}{l}
v_{a}=162.63 \cos \omega t, \\
v_{b}=187.03 \cos \left(\omega t-120^{\circ}\right), \\
v_{c}=138.24 \cos \left(\omega t+120^{\circ}\right) .
\end{array}\right.
$$

The voltage amplitude of the B phase increases by $15 \%$ compared with that of the A phase, and the voltage amplitude of the $\mathrm{C}$ phase decreases by $15 \%$ compared with that of the A phase. The fundamental wave frequency is $360 \sim 800 \mathrm{~Hz}$. According to the standard of DO-160G, the change rate is a linear change of $200 \mathrm{~Hz} / \mathrm{s}$.

Figure 13 shows that the angular frequency $\omega_{g}$ output by the PLL ultimately changes linearly at a rate of $400 \pi \mathrm{rad} / \mathrm{s}^{2}$, and the phase angle $\theta_{g}$ also attains a stable state. Furthermore, the linear Kalman filter PLLs added three kinds of SOGIs that can restrain the three-phase voltage imbalance of aviation frequency conversion power supply.

4.3. The Three-Phase Voltage of Aviation Variable Frequency Power Supply Contains DC Component. The three-phase voltage is expressed as follows:

$$
\left\{\begin{array}{l}
v_{a}=162.63 \cos \omega t+10, \\
v_{b}=162.63 \cos \left(\omega t-120^{\circ}\right)-10, \\
v_{c}=162.63 \cos \left(\omega t+120^{\circ}\right)-10 .
\end{array}\right.
$$

The aviation variable frequency power supply contains a DC component as shown in equation (27). The fundamental 


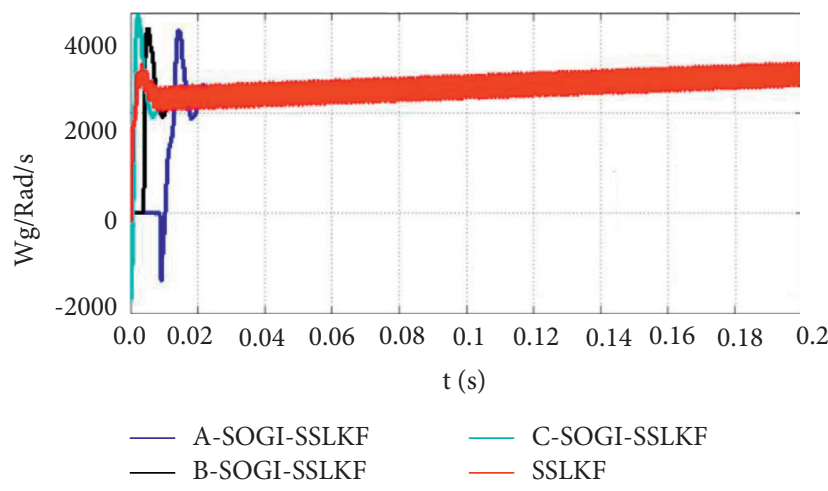

(a)

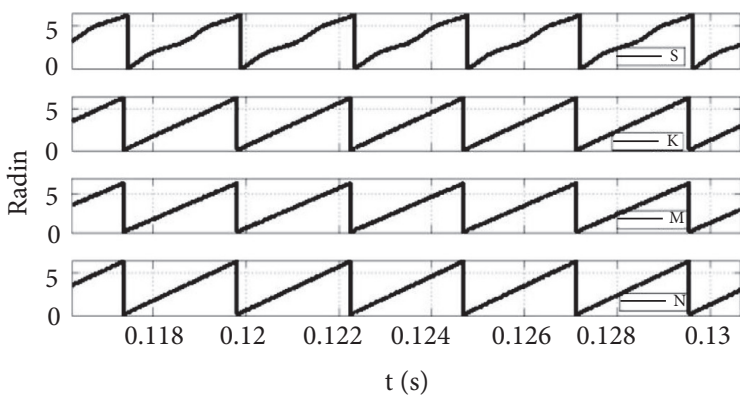

(b)

FIGURE 13: Simulation results of three-phase voltage imbalance of aviation inverter power: $(\mathrm{a}) \omega_{g}$; (b) $\theta_{g}$ (S represents SSLKF; K represents ASOGI-SSLKF; M represents B-SOGI-SSLKF; N stands for C-SOGI-SSLKF).

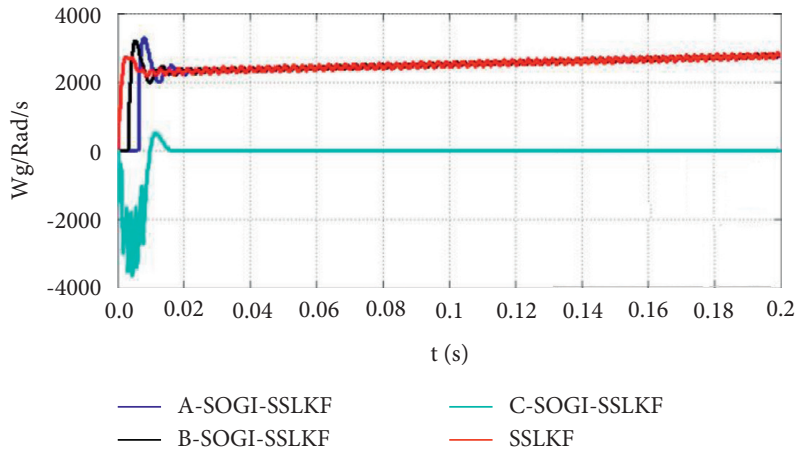

(a)

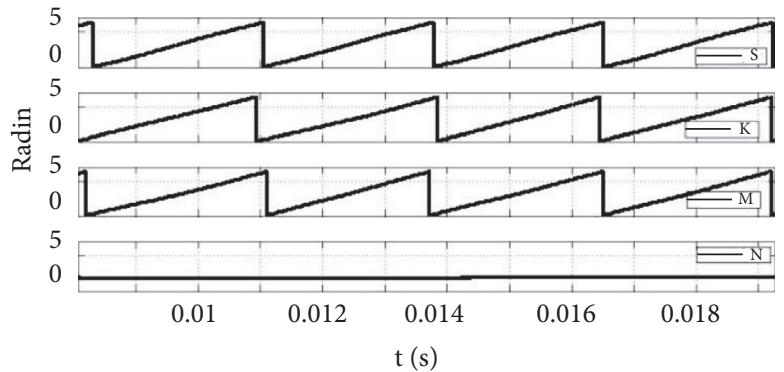

(b)

FIGURE 14: Simulation results of three-phase voltage with DC component of aviation frequency converter: (a) $\omega_{g}$; (b) $\theta_{g}$ (S represents SSLKF; K represents A-SOGI-SSLKF; M represents B-SOGI-SSLKF; N stands for C-SOGI-SSLKF).

wave frequency is $360 \sim 800 \mathrm{~Hz}$, and the change rate is a linear change of $200 \mathrm{~Hz} / \mathrm{s}$ according to DO-160G standard. The whole system parameters are shown in Section 4.1, and the simulation waveform is shown in Figure 14.

According to Figure 14, the angular frequency $\omega_{g}$ output by the PLL ultimately changes linearly at a rate of $400 \pi \mathrm{rad} /$ $s^{2}$, and the phase angle $\theta_{g}$ also attains a stable state. Besides, the linearity of the phase angle is excellent. However, the linear Kalman filter PLL with C-type SOGI fails to realize phase locking. This result indicates that the C-type SOGI has no inhibitory effect on the DC component. On the contrary, the linear Kalman filter PLL has a brilliant inhibitory effect on the DC component of the aviation frequency conversion power supply, and the A-type SOGI and B-type SOGI also have a practical inhibitory effect on the DC component.

From the above simulation, it can be seen that A-type SOGI and B-type SOGI combined with the linear Kalman filter PLL can inhibit the high harmonic content, three-phase voltage imbalance, and DC component of the aviation variable frequency power supply voltage. Moreover, B-type SOGI has better dynamic performance. C-type SOGI can only suppress the three-phase voltage imbalance. In addition, the linear Kalman filter PLL can restrain the DC component.

\section{Conclusion}

Abundant distributed generators need to be connected to the power grid through the converter as the power interface, while the current source converter needs the external power grid to provide a stable reference voltage and synchronize with the power grid voltage through the phase-locked loop. The present work aims to solve the existing problems of aviation frequent conversion power supply in the microgrid, such as excessive harmonics, voltage imbalance, and DC component, to guarantee the efficient and stable flight of the aircraft, unmanned aerial vehicle, and other aircraft. Therefore, SOGIs of three structures are integrated with the linear Kalman filter PLL. Moreover, for the high-order PLL system with strong nonlinearity, the state equations of the whole PLL are derived, and a stable region of the system is obtained by the solution of the state equations. Finally, simulation and experimental verification are carried out in this stable region to select the appropriate SOGI and linear Kalman filter PLL for different aviation power supply voltages to achieve precise phase locking. The different factors and influencing conditions of the studied dynamic high-order PLL system are analyzed after setting fixed parameters based on laboratory equipment. In specific 
application, it should be combined with the environment and physical limitations of converter in aviation variable frequency power supply, and the corresponding coefficient setting limits need to be further studied.

\section{Data Availability}

The data used to support the findings of this study are included within the article.

\section{Conflicts of Interest}

The authors declare that they have no conflicts of interest.

\section{References}

[1] S. A. Alavi, K. Mehran, Y. Hao, A. Rahimian, H. Mirsaeedi, and V. Vahidinasab, "A distributed event-triggered control strategy for DC microgrids based on a publish-subscribe model over industrial wireless sensor networks," IEEE Transactions on Smart Grid, vol. 10, no. 4, pp. 4323-4337, 2018.

[2] S. Sanober, I. Alam, S. Pande et al., "An enhanced secure deep learning algorithm for fraud detection in wireless communication," Wireless Communications and Mobile Computing, vol. 2021, Article ID 6079582, 14 pages, 2021.

[3] K. W. E. Chen, "Comparative study of AC/DC converters for more electronic aircraft," in Proceedings of the Seventh International Conference on Power Electronics and Variable Speed Drives, pp. 299-304, London, UK, September 1998.

[4] G. Gong, M. L. Heldwein, U. Drofenik, J. Minibock, K. Mino, and J. W. Kolar, "Comparative evaluation of three-phase high-power-factor AC-DC converter concepts for application in future more electric aircraft," IEEE Transactions on Industrial Electronics, vol. 52, no. 3, pp. 727-737, 2005.

[5] A. Bellini and S. Bifaretti, "Performances of a PLL based digital filter for double-conversion UPS," in Proceedings of the 13th International Power Electronics and Motion Control Conference, pp. 490-497, Poznan, Poland, September 2008.

[6] A. Bellini, S. Bifaretti, and V. Iacovone, "Robust PLL algorithm for three-phase grid-connected converters," EPE Journal, vol. 20, no. 4, pp. 22-30, 2010.

[7] S. Bifaretti, P. Zanchetta, and E. Lavopa, "Comparison of two three-phase PLL systems for more electric aircraft converters," IEEE Transactions on Power Electronics, vol. 29, no. 12, pp. 6810-6820, 2014.

[8] S. Golestan, J. M. Guerrero, and J. C. Vasquez, "Steady-state linear Kalman filter-based PLLs for power applications: a second look," IEEE Transactions on Industrial Electronics, vol. 65, no. 12, pp. 9795-9800, 2018.

[9] M. Tang, S. Bifaretti, S. Pipolo, S. Odhano, and P. Zanchetta, "A novel repetitive controller assisted phase-locked loop with self-learning disturbance rejection capability for three-phase grids," IEEE Journal of Emerging and Selected Topics in Power Electronics, vol. 8, no. 2, pp. 1870-1879, 2020.

[10] K. Ni, Y. Liu, Z. Mei et al., "Electrical and electronic technologies in more-electric aircraft: a review," IEEE Access, vol. 7, pp. 76145-76166, 2019.

[11] F. Cupertino, E. Lavopa, P. Zanchetta, M. Sumner, and L. Salvatore, "Running DFT-based PLL algorithm for frequency, phase, and amplitude tracking in aircraft electrical systems," IEEE Transactions on Industrial Electronics, vol. 58, no. 3, pp. 1027-1035, 2011.
[12] Z. Xin, X. Wang, Z. Qin, M. Lu, P. C. Loh, and F. Blaabjerg, "An improved second-order generalized integrator based quadrature signal generator," IEEE Transactions on Power Electronics, vol. 31, no. 12, pp. 8068-8073, 2016.

[13] M. A. Akhtar and S. Saha, "An adaptive frequency-fixed second-order generalized integrator-quadrature signal generator using fractional-order conformal mapping based approach," IEEE Transactions on Power Electronics, vol. 35, no. 6, pp. 5548-5552, 2020.

[14] M. Guo, Z. Wu, and H. Qin, "Harmonics reduction for resolver-to-digital conversion via second-order generalized integrator with frequency-locked loop," IEEE Sensors Journal, vol. 21, no. 6, pp. 8209-8217, 2021.

[15] J. M. L. da Fonseca, F. K. d. A. Lima, F. L. Tofoli, and C. G. C. Branco, "Three-phase phase-locked loop algorithm and application to a static synchronous compensator," Electric Power Systems Research, vol. 192, Article ID 106924, 2021.

[16] P. Rodríguez, A. Luna, R. Muñoz-Aguilar, I. EtxeberriaOtadui, R. Teodorescu, and F. Blaabjerg, "A stationary reference frame grid synchronization system for three-phase grid-connected power converters under adverse grid conditions," IEEE Transactions on Power Electronics, vol. 27, no. 1, pp. 99-112, 2012.

[17] Q. Hu, L. Fu, F. Ma, and F. Ji, "Large signal synchronizing instability of PLL-based VSC connected to weak AC grid," IEEE Transactions on Power Systems, vol. 34, no. 4, pp. 3220-3229, 2019.

[18] H. Wu and X. Wang, "Design-oriented transient stability analysis of PLL-synchronized voltage-source converters," IEEE Transactions on Power Electronics, vol. 35, no. 4, pp. 3573-3589, 2020.

[19] M. Bravo, A. Garcés, O. D. Montoya, and C. R. Baier, "Nonlinear analysis for the three-phase PLL: a new look for a classical problem," in Proceedings of the IEEE Workshop on Control and Modeling for Power Electronics, pp. 1-6, Padua, Italy, June 2018.

[20] J. Zhao, M. Huang, H. Yan, C. K. Tse, and X. Zha, "Nonlinear and transient stability analysis of phase-locked loops in gridconnected converters," IEEE Transactions on Power Electronics, vol. 36, no. 1, pp. 1018-1029, 2021.

[21] Z. Chen, M. Lin, Y. Zheng, Z. Wei, S. Huang, and S. Zou, "Single-Event transient characterization of a radiation-tolerant charge-pump phase-locked loop fabricated in $130 \mathrm{~nm}$ PD-SOI technology," IEEE Transactions on Nuclear Science, vol. 63, no. 4, pp. 2402-2408, 2016.

[22] W. Xu, C. Huang, and H. Jiang, "Analyses and enhancement of linear Kalman-filter-based phase-locked loop," IEEE Transactions on Instrumentation and Measurement, vol. 70, pp. 1-10, 2021.

[23] M. Miao, W. Cai, and X. Li, "Parameter estimation of gammagamma fading with generalized pointing errors in FSO systems," Wireless Communications and Mobile Computing, vol. 2021, Article ID 1301878, 14 pages, 2021.

[24] M. Yan, X. Lou, and Y. Wang, "Channel noise optimization of polar codes decoding based on a convolutional neural network," Wireless Communications and Mobile Computing, vol. 2021, Article ID 1434347, 10 pages, 2021.

[25] O. J. Famoriji and T. Shongwe, "Source localization of EM waves in the near-field of spherical antenna array in the presence of unknown mutual coupling," Wireless Communications and Mobile Computing, vol. 2021, Article ID 3237219, 14 pages, 2021.

[26] M. Peng, W. Liu, T. Wang, and Z. Zeng, "Relay selection joint consecutive packet routing scheme to improve performance 
for wake-up radio-enabled WSNs," Wireless Communications and Mobile Computing, vol. 2020, Article ID 7230565, 32 pages, 2020.

[27] M. Tang, S. Bifaretti, S. Pipolo, A. Formentini, S. Odhano, and P. Zanchetta, "A novel low computational burden dual-observer phase-locked loop with strong disturbance rejection capability for more electric aircraft," IEEE Transactions on Industry Applications, vol. 57, no. 4, pp. 3832-3841, 2021.

[28] K. S. Adu-Manu, F. A. Katsriku, J. D. Abdulai, and F. Engmann, "Smart river monitoring using wireless sensor networks," Wireless Communications and Mobile Computing, vol. 2020, Article ID 8897126, 19 pages, 2020.

[29] H. Wang, Y. Yang, X. Ge, S. Li, and Y. Zuo, "Speed-sensorless control of linear induction motor based on the SSLKF-PLL speed estimation scheme," IEEE Transactions on Industry Applications, vol. 56, no. 5, pp. 4986-5002, 2020. 